J. Pijar MIPA, Vol. VI No.1, Maret : 9 - 12

ISSN 1907-1744

\title{
SEISMOGRAF REFRAKSI DENGAN SUMBER GELOMBANG WEIGH DROP
}

\author{
Muhammad Zuhdi \\ FKIP Universitas Mataram \\ Email : zuhdiunram@gmail.com
}

\begin{abstract}
Abstrak : Telah dibuat seimograf refraksi dengan sumber gelombang weigh drop berupa bola besi yang di jatuhkan 2 meter dari landasan. Sumber gelombang ini mampu memberikan sinyal pada geophone hingga jarak 150 meter. Prinsip kerja seismograf refraksi adalah mengukur waktu tiba gelombang tercepat (fisrt arrival time) dari sumber menuju geophone. Untuk jarak pendek, gelombang tercepat adalah gelombang langsung, sedangkan untuk jarak selebihnya gelombang tercepat adalah gelombang refraksi. Waktu tiba gelombang tercepat diukur dengan instrumen elektronik dengan ketelitian hingga 0,1 milli sekon. Hasil ujicoba menunjukkan bahwa seismogram mampu mendeteksi perlapisan hingga kedalaman 5 meter dengan jarak horizontal mencapai 150 meter.
\end{abstract}

Kata kunci : Seismograf, refraksi, weigh drop

\section{REFRACTION SEISMOGRAPH WITH WEIGH DROP SOURCE}

Abstract : Refraction seismograph is have been made with wave source of weigh drop made of iron ball from altitude 2 metre from the ground. Source of this wave can give geophone signal till 150 metre apart. Principal of refraction seismograph is to measure first arrival of incoming wave to geophone. For short distance, first arrival wave is direct wave, while for the medium and long distance first arrival wave is refraction wave. Arrival time is measured with electronic instrument with errors till 0,1 millisecond. Result of instrument trial indicate that seismogram can detect some layers till 5 metre deep with horizontal distance till 150 metre.

Key words : Seismograph, refraction, weigh drop

\section{PENDAHULUAN}

Seismik refraksi merupakan salah satu metoda yang cukup penting dalam metode seismik sebagai salah satu metoda geofisika. Metoda geofisika seismik dibagi menjadi dua bagian, yaitu yaitu metoda seimik refleksi dan metoda sismik refraksi.

Seismik refraksi biasanya digunakan untuk mendeteksi perlapisan dangkal. Kegunaan dari metoda ini antara lain mencari ketebalan soil, mencari mineral, menentukan kedalaman batuan yang digunakan sebagai pondasi bangunan gedung, jalan raya dan dam.

Metoda seismik refraksi didasarkan pada perbedaan kecepatan perambatan golombang seismik pada tiap-tiap perlapisan. Biasanya, semakin dalam perlapisan tanah maka akan memiliki kekerasan yang makin besar, sehingga kecepatan perambatan gelombang seismik pada perlapisan yang lebih dalam akan semakin besar[1].

Metoda seismik refraksi pertama kali dilakukan oleh Gough [2]. Gough menggunakan palu sebagai sumber gelombangnya. Langkah yang dikerjakan adalah mengukur waktu rambat gelombang tercepat dari sumber menuju penerima (geophone) dengan berbagai variasi jarak antara sumber dan penerima. Hasil dari pengukuran ini ditampilkan dalam bentuk grafik waktu rambat tarhadap jarak sumber ke penerima. Dari grafik waktu rambat ini dapat dilakukan interpetasi untuk menentukan kedalaman dan cepat rambat gelombang seismik pada tiap perlapisan, sehingga dapat diperlihatkan bentuk struktur tanahnya.

Instrumen yang digunakan dalam metoda ini adalah peralatan yang dapat menghitung waktu rambat gelombang tercepat dari sumber menuju geophone secara akurat. Pengukuran ini dapat dilakukan dengan menggunakan signal anthancement seismograph. Namun alat ini mempunyai harga yang cukup mahal, sedangkan metoda ini dapat dilakukan dengan alat yang lebih sederhana.
Pada perkembangan berikutnya Marhadi mencoba membuat seismograf refraksi yang dapat mengukur waktu rambat gelombang dari sumber menuju geophone. Alat ini mempunyai tampilan berupa LED, yang menunjukkan angka biner [3]. Alat ini mempunyai beberapa kelemahan, antara lain pembacaan angka yang sulit dan mudah terganggu oleh noise.

Perkembangan berikutnya Affandi mencoba untuk menyempurnakan alat ini dengan mengunakan cara koinsiden untuk mengurangi noise, dan menggunakan tampilan seven segmen, sehingga mudah dalam pembacaannya [4]. Kelemahan alat ini memerlukan catu daya yang besar dan tidak portabel, serta redusi noise tidak optimal.

Untuk mengatasi kelemahan-kelemahan tersebut, Zuhdi mencoba membuat seismograf refraksi dengan menggunakan tampilan LCD (Liquid Crystal Diaplay) yang memakan daya cukup kecil dan dilengkapi dengan detektor noise [5]. Kelemahan dari alat ini adalah gelombang seismik yang dihasilkan oleh sumber gelombang kecil. Sehingga, jarak antara sumber gelombang dan geophone sangat terbatas. Hal tersebut disebabkan karena sumber gelombangnya berasal dari tenaga manusia.

Kelemahan-kelemahan peralatan ini dapat diatasi dengan mengunakan sumber gelombang yang lebih besar. Sumber gelombang yang digunakan adalah Weigh Drop yang berupa sebuah bola besi yang digantungkan pada ketinggian tertentu kemudian dilepaskan menuju tanah dan bertumbukan dengan target yang merupakan sumber gelombang seismik. Besar energi gelombang seismik yang dihasilkan tergantung pada ketinggian Weigh Drop.

Dengan sumber gelombang berupa Weigh Drop maka seismograf refraksi dapat mendeteksi lapisan dengan kedalaman lebih besar dibandingkan dengan sumber gelombang palu. 


\section{TINJAUAN PUSTAKA}

Parameter fisis yang diukur pada seismik refraksi adalah waktu tiba tercepat gelombang seismik dari sumber (weigh drop) menuju penerima (geophone). Waktu tiba tercepat gelombang seismik ini disebut first arrival time[6]. Dengan mengubah jarak sumber ke geophone maka waktu tiba tercepat gelombang seismik juga berubah.

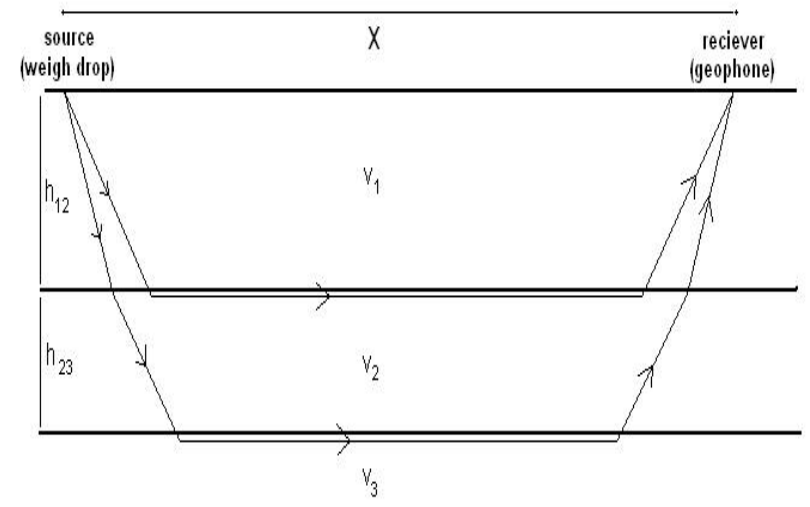

Gambar 1. Penjalaran gelombang seısmık darı sumber (weigh drop) menuju penerima (geophone).

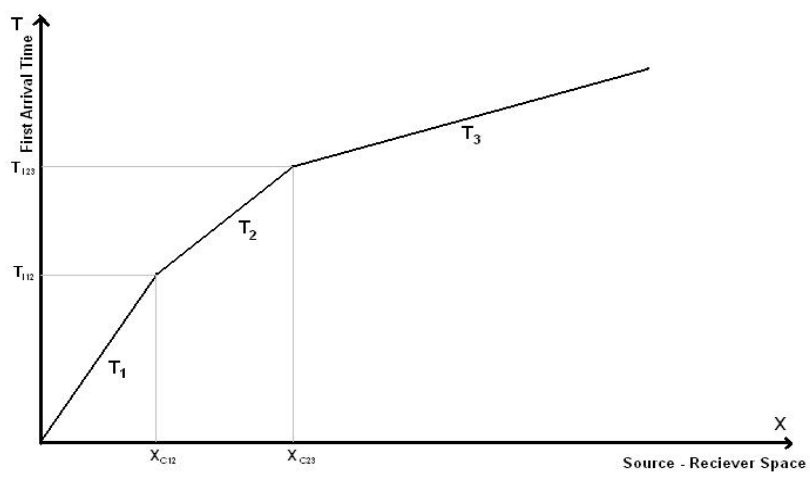

Gambar 2. Grafik waktu tiba dari gelombang tercepat.

Gambar 1 menunjukkan penjalaran gelombang seismik dari sumber (weigh drop) menuju penerima (geophone). Gambar 2 adalah grafik travel time dari gelombang tercepat.

Untuk jarak tertentu gelombang tercepat adalah gelombang langsung (direct wave) yang merambat melalui lapisan 1. Persamaan gelombang seismik ini adalah:

$$
\mathrm{T}_{1}=\mathrm{X} \mathrm{v}_{1}^{-1} \text {. }
$$

Gelombang seismik tercepat kedua adalah gelombang yang merambat melalui lapisan ke dua dengan persamaan :

$$
\mathrm{T}_{2}=\mathrm{X} \mathrm{v}_{2}^{-1}+2 \mathrm{~h}_{12}\left(\mathrm{v}_{1} \mathrm{v}_{2}\right)^{-1}\left(\mathrm{v}_{2}{ }^{2}-\mathrm{v}_{1}{ }^{2}\right)^{-1 / 2}
$$

Gelombang seismik tercepat berikutnya adalah gelombang yang merambat melalui lapisan ke tiga dengan persamaan :

$$
\mathrm{T}_{3}=\underset{{ }_{1}\left(\mathrm{v} \mathrm{v}_{3}{ }^{2}-\mathrm{v}_{2}{ }^{2}\right)^{-1 / 2}+2 \mathrm{~h}_{12}\left(\mathrm{v}_{1} \mathrm{v}_{3}\right)^{-1}\left(\mathrm{v}_{3}{ }^{2}-\mathrm{v}_{1}\right)^{-1 / 2}+2 \mathrm{~h}_{23}\left(\mathrm{v}_{2} \mathrm{v}_{3}\right)^{-}}{ }
$$

Nilai $\mathrm{v}_{1}, \mathrm{v}_{2}, \mathrm{v}_{3}$ didapatkan dari slope grafik sebagai mana ditunjukkan oleh gambar 2. Substitusi nilai $\mathrm{X}_{\mathrm{C} 12}$ dan $\mathrm{X}_{\mathrm{C} 23}$ pada persamaan (1), (2) dan (3) diatas akan didapatkan nilai $h_{12}$ (ketebalan lapisan pertama) dan $h_{23}$ (ketebalan lapisan kedua).

Ketebalan lapisan pertama adalah:

$$
\mathrm{h}_{12}=1 / 2 \mathrm{X}_{\mathrm{C} 12}\left(\mathrm{v}_{1}-\mathrm{v}_{2}\right)^{1 / 2}\left(\mathrm{v}_{1}+\mathrm{v}_{2}\right)^{-1 / 2}
$$

Ketebalan lapisan kedua adalah:

$$
\begin{aligned}
\mathrm{h}_{23}= & 1 / 2 \mathrm{v}_{1} \mathrm{v}_{2}\left(\mathrm{v}_{3}^{2}-\mathrm{v}_{2}^{2}\right)^{-1 / 2}\left\{\left(\mathrm{X}_{\mathrm{C} 23} / \mathrm{v}_{2}\right)-\left(\mathrm{X}_{\mathrm{C} 23} / \mathrm{v}_{3}\right)\right. \\
& -2 \mathrm{~h}_{12}\left(\mathrm{v}_{2} \mathrm{v}_{3}\right)^{-1}\left(\mathrm{v}_{3}{ }^{2}-\mathrm{v}_{2}^{2}\right)^{1 / 2} \\
& \left.+2 \mathrm{~h}_{12}\left(\mathrm{v}_{1} \mathrm{v}_{2}\right)^{-1}\left(\mathrm{v}_{2}{ }^{2}-\mathrm{v}_{1}{ }^{2}\right)^{1 / 2}\right\}
\end{aligned}
$$

Nilai jarak $\mathrm{X}_{\mathrm{C} 12}$ didapat dari grafik pada gambar 2. Pada jarak $\mathrm{X}_{\mathrm{C} 12}$ ini gelombang seismik tiba tercepat dari lapisan 1 sama dengan gelombang seismik tiba tercepat dari lapisan 2, dengan demikian $\mathrm{T}_{\mathrm{il} 2}=\mathrm{T}_{1}=\mathrm{T}_{2}$.

Nilai jarak $\mathrm{X}_{\mathrm{C} 23}$ didapat dari grafik pada gambar 2. Pada jarak $\mathrm{X}_{\mathrm{C} 23}$ ini gelombang seismik tiba tercepat dari lapisan 2 sama dengan gelombang seismik tiba tercepat dari lapisan 3, dengan demikian $\mathrm{T}_{\mathrm{i} 23}=\mathrm{T}_{2}=\mathrm{T}_{3}$.

\section{METODE PENELITIAN}

Penelitian ini dilakukan dalam beberapa tahap.

Tahap pertama yaitu merakit peralatan, tahap kedua adalah uji coba alat di lapangan dan tahap ketiga melakukan pendeteksian perlapisan dangkal.

Instrumen yang dibuat meliputi:

1. Rangkaian utama seismograf yang berisi pengatur gerbang, gerbang, pencacah, dekoder, dan tampilan.

2. Rangkaian penguat transducer dan penguat additional yang masing-masing terdiri dari tiga buah penguat dan pembentuk pulsanya.

3. Rangkaian osilator berupa sebuah generator pulsa kotak $1 \mathrm{MHz}$, dengan kristal sebagai pengacu frekwensi.

4. Sumber gelombang berupa weigh drop dan penerima gelombang berupa geophone.

\section{Rangkaian Utama Seismograf}

Rangkaian utama seismograf terdiri dari pengatur gerbang, gerbang, pencacah, dekoder, dan tampilan.

Pencacah yang digunakan adalah pencacah BCD tiga angka yang diambil dari 2 buah IC MC 14553. Pencacah ini mendapat masukan dari tiga buah digit select (DS) yaitu DS1, DS2, dan DS3 yang akan membaca tiga angka secara bergantian. Keluaran dari pencacah ini berupa kode biner empat jalur yang akan diumpankan pada masukan decoder.

Decoder adalah pencacah yang digunakan untuk mengubah kode biner menjadi angka tujuh ruas. Rangkaian seismograf ini terdiri dari empat buah decoder yang dibuat dari empat buah IC MC 14543. Keluaran dari decoder ini diumpankan pada masukan LCD yang akan menampilkan angka tujuh ruas. Setiap IC membaca angka dengan orde berbeda. IC pertama membaca angka dengan orde 0,1 milli detik yang diambil dari jalur DS3, IC Kedua membaca angka dengan orde 1 milli detik diambil dari jalur DS1, IC ketiga dengan orde 10 milli detik dari jalur DS2, dan IC keempat dengan orde 100 milli detik dari jalur DS3.

Rangkaian ini menggunakan tampilan dari sebuah LCD (Liquid Crystal Dispay) tiga setengah angka yang masing-masing membentuk angka tujuh ruas ruas. LCD ini sangat cocok digunakan untuk seismograf ini, selain memakan daya yang cukup kecil, LCD ini juga cukup memenuhi kebutuhan penelitian karena mudah pembacaannya. 


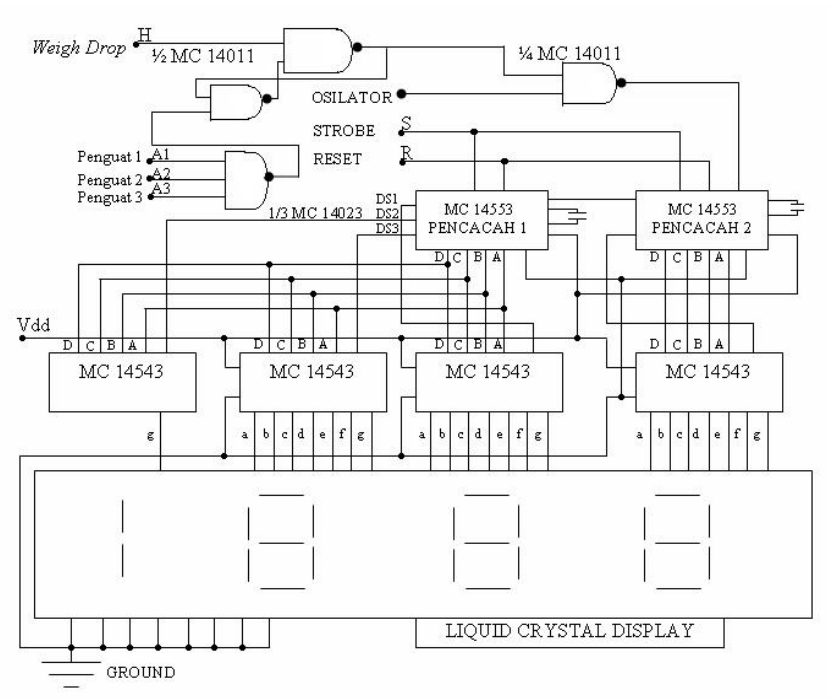

Gambar 3.1 Tampilan sebuah LCD

\section{Rangkaian Penguat}

Rangkaian penguat ini terdiri dari tiga buah penguat dengan pembentuk pulsanya. Rangkian terdiri dari penguat transducer dengan transistor C945, dan penguat lanjutan berupa penguat additional dengan 2 buah OpAmp LM 324. Hasil dari penguatan geophone ini pada sebuah monostable multivibrator (MSMV), yang diambil dari IC MC 14538. MSMV ini dilengkapi dengan schmit trigger.
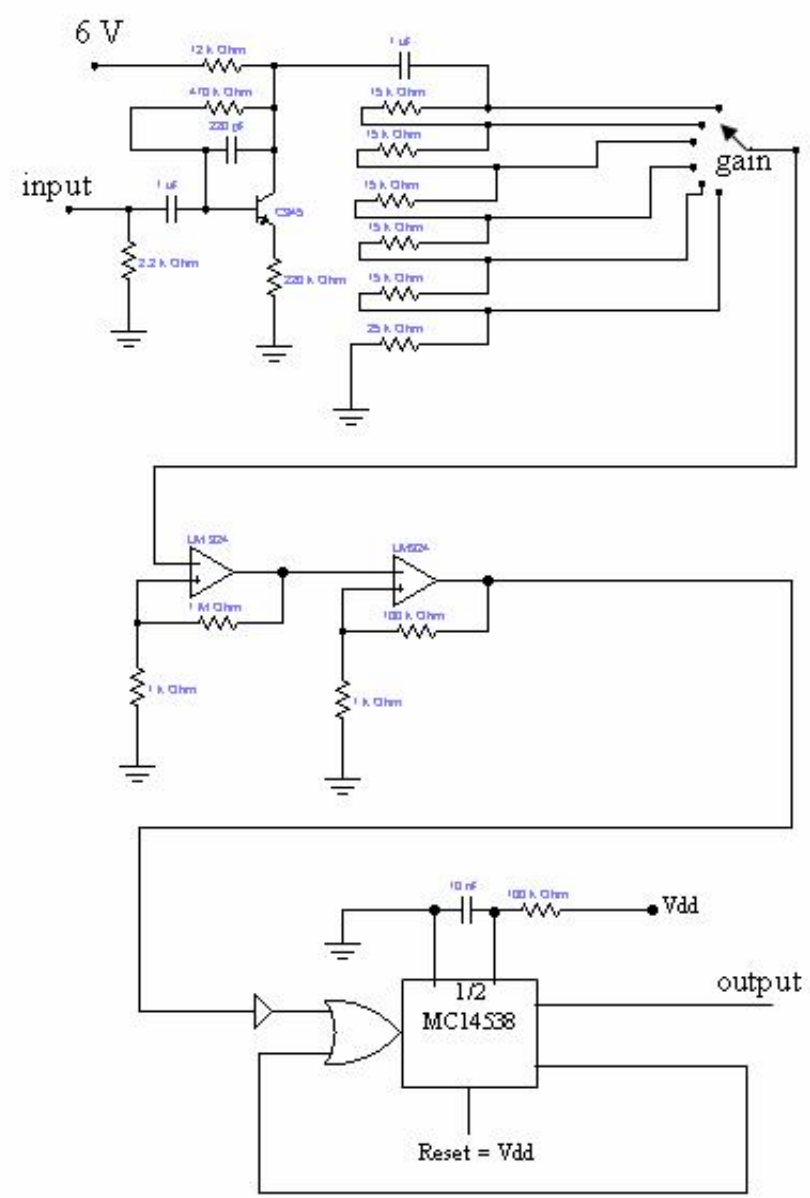

Gambar 3.2 Rangkaian Penguat
MSMV ini merubah sinyal goephone yang sudah diperkuat menjadi pulsa kotak sepanjang 3 millisekon. Rangkain penguat beserta pembentuk pulsanya ditunjukkan olaeh gambar 3.2. Rangkaian penguat ini berjumlah 3 buah masing-masing untuk 1 geophone.

\section{Rangkaian Osilator}

Rangkaian osilator ini berupa generator pulsa kotak $1 \mathrm{MHz}$, dengan menggunakan kristal sebagai pemicu frekwensi. Gambar 3.3 menunjukkan rangkaian osilator ini.

Rangkaian terdiri dari empat buah gerbang nand dua masukan yang dibuat dari sebuah IC MC 14011, yang merupakan gerbang nand dua masukan berempat. Sebagai pemicu getaran digunakan sebuah kristal $1 \mathrm{MHz}$. Keluaran dari osilator ini diumpankan pada masukan gerbang pada rangkaian utama seismograf.

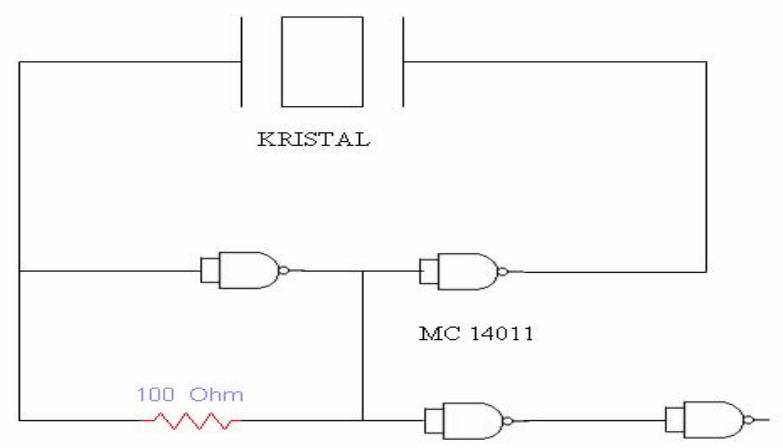

Gambar 3.3 Rangkaian Osilator

\section{Weigh Drop}

Weigh drop digunakan sebagai alat pembangkit gelombang seismik. Energi gelombang seismik yang dihasilkan tergantung pada tinggi weigh drop terhadap landasan dan juga massa weigh drop. Massa weigh drop yang dipergunakan dalam penelitian ini sebesar $15 \mathrm{~kg}$ dengan tinggi 2 meter dari landasan.

\section{Uji Peralatan di Lapangan}

Uji Peralatan di Lapangan menunjukkan bahwa sumber gelombang seismik berupa weigh drop dengan massa $15 \mathrm{~kg}$ mampu mendeteksi perlapisan dengan line sepanjang $150 \mathrm{~m}$. Uji coba peralatan ini dilakukan pada daerah aluvial. Perlapisan pertama didapatkan memiliki ketebalan 1,2m hingga 1,3m sedangkan perlapisan kedua memiliki ketebalan $0,4 \mathrm{~m}$ hingga $0,5 \mathrm{~m}$.

\section{HASIL DAN PEMBAHASAN}

Instrument ini terdiri dari 3 bagian unit terpisah. Unit weigh drop terdiri dari bola besi bermassa $15 \mathrm{~kg}$ dan tripot beserta katrolnya. Unit geophone terdiri dari 3 buah geophone. Unit Seismograf terdiri dari rangkaian penguat, osilator dan rangkaian utama.

Instrumen ini mampu mengukur waktu tiba tercepat gelombang seismik dari weigh drop menuju geophone dengan ketelitian 0,1 milli sekon.

Weigh drop bermassa $15 \mathrm{~kg}$ mampu menghasilkan gelombang seismik yang kekuatanya dapat terdeteksi oleh geophone dengan jarak hingga $150 \mathrm{~m}$. 
Penggunaan weigh drop ini sangat signifikan pengaruhnya terhadap kemampuan deteksi seismograf, dibandingkan penggunaan palu yang hanya bisa mendeteksi hingga jarak $50 \mathrm{~m}$.

\section{DAFTAR PUSTAKA}

[1] Garland, GD, 1971, Intoduction to Geophysics, Mantel, Core and Crust. WB Saunders Company, Toronto.

[2] Gough, DI, 1952, A New Instrument for Seismic Exploration at Very Short Ranges. Geophysics vol 7.

[3] Marhadi, 1975, Seismik Refraksi dalam ukuran kecil instrument dan Interpretasi Data, Skripsi, UGM, Yogyakarta.

[4] Affandi, Y., 1977. Penggunaan Cara Koinsidensi dalam Seismograf Bias Untuk Penyelidikan Seismik Bias Dangkal. Skripsi, UGM, Yogyakarta.

[5] Zuhdi, M., 1997, Pembuatan Seismograf Refraksi Koinsidensi Tiga Geophone dan Penggunaanya untuk mendeteksi perlapisan adngkal.

[6] Sheriff, RE., 1976, Encyclopedic Dictionary of Exploration Geophysics. SEG, Tulsa, Oklahoma. 